\title{
Severe inflammatory upper airway stenosis in ulcerative colitis
}

\author{
H. Rickli*, C. Fretz**, M. Hoffman', A. Walser ${ }^{+}$, A. Knoblauch*
}

\begin{abstract}
Severe inflammatory upper airway stenosis in ulcerative colitis. H. Rickli, C. Fretz, M. Hoffman, A. Walser, A. Knoblauch. CERS Journals Ltd 1994.

ABSTRACT: Severe upper airway stenosis was diagnosed in a 23 year old woman who presented with hoarseness, cough and dyspnoea 8 yrs after initial diagnosis of ulcerative colitis. The respiratory symptoms worsened over the next few months, the patient eventually developing dysphagia and ultimately severe upper airway obstruction. The narrowest site was the glottis, which was severely stenosed by inflammatory swellings. Systemic corticosteroids led to rapid clinical improvement and restoration of normal airway patency within a few months.

Ulcerative colitis is frequently associated with extraintestinal inflammatory manifestations. In the respiratory tract these usually take the form of chronic bronchitis, which occasionally develops into bronchiectasis. This case confirms that the inflammation can also involve the larynx and large airways.

Eur Respir J., 1994, 7, 1899-1902.
\end{abstract}

*Division of Pulmonary Medicine, Dept of Medicine, and Depts of **Radiology, and Otorhinolaryngology, Head and Neck Surgery, Kantonsspital St. Gallen, St. Gallen, Switzerland. +Dept of Medicine, Kantonales Spital Flawil, Flawil, Switzerland.

Correspondence: A. Knoblauch, Division of Pulmonary Medicine, Kantonsspital Medizin A, CH-9007 St. Gallen, Switzerland

Keywords: Bronchitis, laryngitis, tracheitis, ulcerative colitis, upper airway stenosis

Received: October 271993

Accepted after revision May 281994
Ulcerative colitis is associated in up to $45 \%$ of cases with inflammation of extraintestinal organs. In a study of 202 patients, the joints (26\%), skin (19\%) and eyes (4\%) were the most commonly affected sites [1]. A growing body of literature has recently described inflammatory pulmonary disease accompanying inflammatory bowel disease (IBD) with involvement of the lung parenchyma, airways, pleurae and pulmonary vasculature [2-9]. We report a case of severe but reversible upper airway obstruction due to pseudotumorous inflammation of the larynx, trachea and main bronchi.

\section{Case report}

\section{History}

The patient was a 23 year old nonsmoking female music student, in whom a histologically confirmed diagnosis of ulcerative colitis had been made at $15 \mathrm{yrs}$ of age, following a 6 month history of persistent mucous diarrhoea. On long-term sulphasalazine, she experienced 2-3 colonic attacks each year, which required intermittent oral corticosteroid therapy. A switch from sulphasalazine to mesalazine at the beginning of 1991 produced no change in gastrointestinal symptoms.

During autumn 1991, the patient complained that her voice became easily tired and that she was occasionally hoarse. Laryngoscopy in December 1991 showed mild laryngeal swelling. In July 1992, two months after an attack of colitis was treated with oral corticosteroids, an apparent upper respiratory tract infection led to increasing hoarseness, exertional dyspnoea, nonproductive cough and dysphagia, over a period of 5 weeks. The patient's weight decreased by $7 \mathrm{~kg}$. Despite administration of various antibiotics (roxithromycin, ciprofloxacin, amoxycillin-clavulanic acid/tobramycin, doxycycline), the symptoms worsened and the erythrocyte sedimentation rate and $\mathrm{C}$-reactive protein increased.

\section{Clinical findings}

On September 1 1992, the patient was apyrexial and appeared generally unwell. Her voice was hoarse and there was a predominantly inspiratory stridor. The throat was reddened. A few dry crackles were audible on chest auscultation. There was no cyanosis, clubbing, skin changes or joint swelling. The abdomen was normal on palpation, with normal bowel sounds. Erythrocyte sedimentation rate was $78 \mathrm{~mm} \cdot \mathrm{h}^{-1}$, C-reactive protein 140 $\mathrm{mg} \cdot \mathrm{dl}^{-1}$, and white blood cell count $11.6 \times 10^{9}$ cells $\cdot l^{-1}$ with a normal differential. Haemoglobin was $104 \mathrm{~g} \cdot \mathrm{l}^{-1}$. All other routine laboratory parameters were normal. Serological tests for adenovirus, influenza $\mathrm{A}$ and $\mathrm{B}$, respiratory syncytial virus, Mycoplasma, Legionella, Chlamydia and Coxiella were negative. Antineutrophil cytoplasmic antibodies (ANCA) were negative. Chest X-ray showed marked narrowing of the tracheal air column. Magnetic resonance imaging of the upper chest and neck showed swelling of the tracheal wall (fig. 1). Lung function findings were as follows: forced vital capacity (FVC) $3.11 l$ (71\% predicted), forced expiratory volume in one second $\left(\mathrm{FEV}_{1}\right) 1.57 l$ (41\% pred), $\mathrm{FEV}_{1} /$ vital capacity (VC) $48 \%$ and total lung capacity (TLC) $5.33 l$ (89\% 


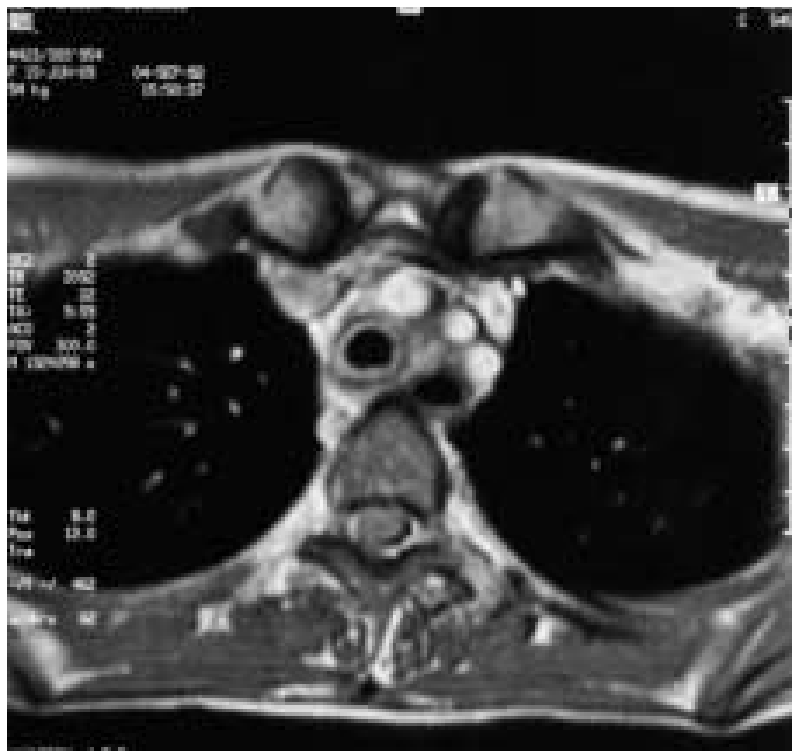

Fig. 1. - The gadolinium enhanced transverse T1-weighted magnetic resonance imaging scan shows a thickened tracheal wall, consistent with inflammatory changes of all layers, most prominent in the mucosa.

pred). Absolute and volume-corrected diffusing capacities were normal. Laryngoscopy revealed symmetrical, pseudotumoral, flesh-coloured swellings in the glottic/ subglottic area, the vocal cords appearing as narrow, white lines (fig. 2). Phonation produced no movement of the vocal cords. The rima glottidis was rigid and too narrow to allow passage of a $5 \mathrm{~mm}$ diameter fibreoptic bronchoscope. The subglottic cavity appeared as a long, narrow and rigid channel. Seven days after the start of corticosteroid therapy the glottic swellings were markedly reduced, movement of the vocal cords was discernible on phonation, and the fibreoptic bronchoscope could be passed. The subglottic cavity, trachea and main bronchi were decreasingly narrowed by nodular mucosal swelling. Minute erythematous foci with white deposits were visible in the mucosa of the membranous trachea. Mucosal biopsy specimens showed respiratory epithelium with severe lymphoplasmacytic inflammation, mild proliferation of granulocytes, including eosinophils, and isolated histiocytic collections. Bronchoalveolar lavage from the middle lobe showed a normal absolute and differential cell count.

\section{Course}

Systemic corticosteroids (initially $1 \mathrm{mg} \cdot \mathrm{kg}^{-1}$ prednisone daily) and topical budesonide rapidly led to a decrease of dyspnoea, with concurrent regression of the obstruction. This was impressively confirmed by a series of flow-volume loops (fig. 3). Erythrocyte sedimentation rate and C-reactive protein both returned to normal.

The prednisone dose was tapered off over the next 7 months, whilst budesonide was continued at a maintenance dose of $400 \mu \mathrm{g}$ daily. Endoscopic findings at follow-up after 8 months were almost normal, although mild laryngotracheobronchial swelling persisted, along with a tendency to vocal fatigue and hoarseness.

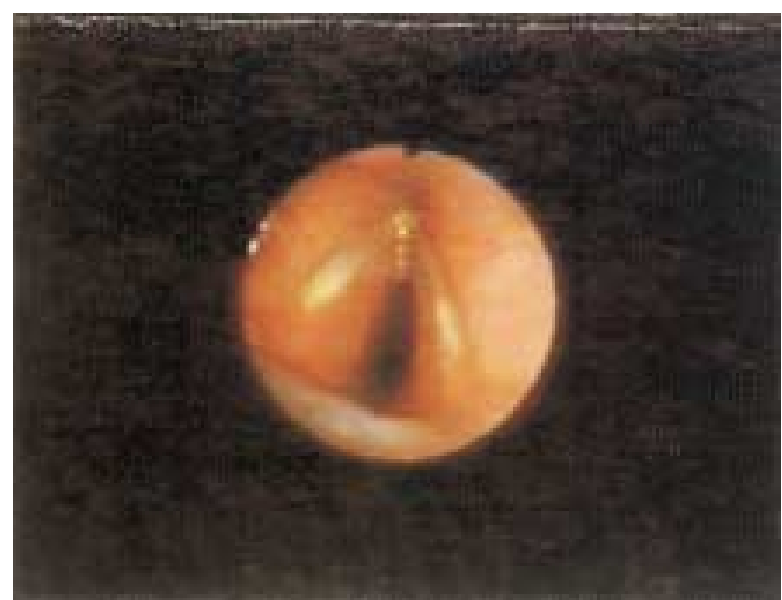

Fig. 2. - The larynx before initiation of corticosteroid therapy. The vocal cords appear as narrow white structures on top of flesh-coloured inflammatory pseudotumours. The vocal cords were immobile on phonation.

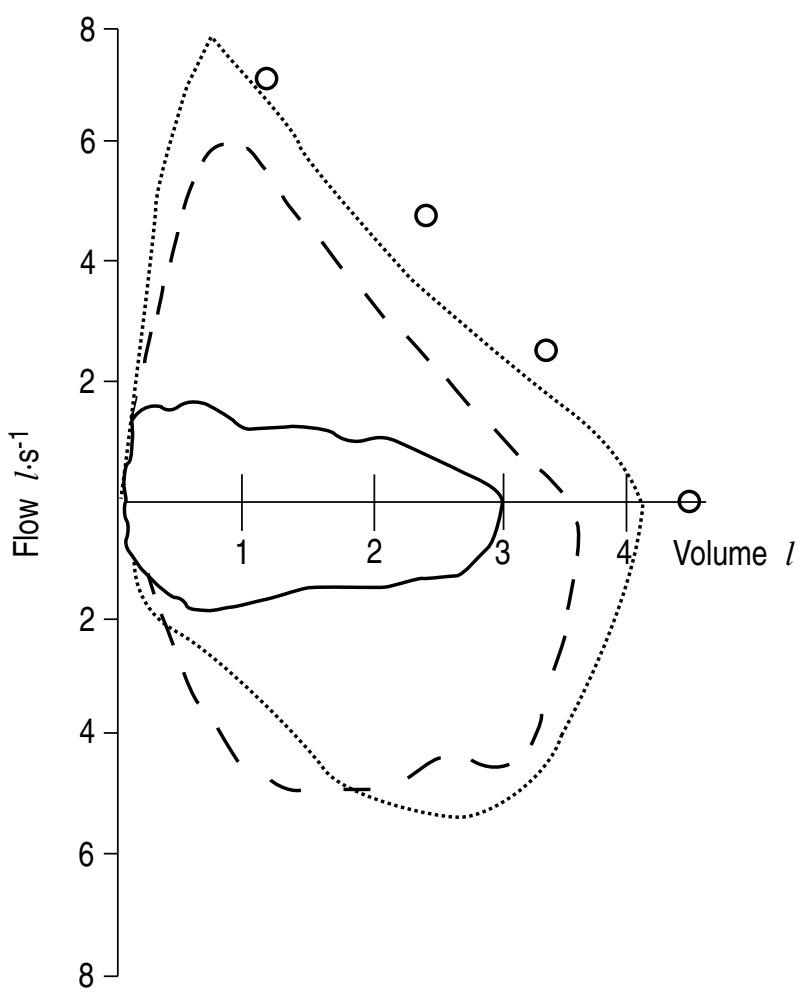

Fig. 3. - Sequence of flow-volume loops (FVL). Before initiation of corticosteroid therapy, the FVL shows rigid upper airway stenosis ( - . After 1 week of oral corticosteroid therapy, there is marked improvement (- - - After 3 months' of therapy, the FVL is approaching normal ( ................ ). Corresponding forced expiratory volume in one second $\left(\mathrm{FEV}_{1}\right): 1.57,3.11$ and $3.69 l$, respectively.

\section{Discussion}

Our patient presented with severe upper airway obstruction due to pseudotumorous swelling of the larynx, trachea and main bronchi. After a 9 month history of unexplained cough, increasing hoarseness, dysphagia and progressive dyspnoea, the patient's problem was eventually recognized when inspiratory stridor at rest led to bronchoscopy. 
Initially, the most conspicuous endoscopic findings were marked increase in mucosal volume causing severe stenosis in the region of the vocal cords.

Varied patterns of respiratory involvement in inflammatory bowel disease have been reported, including airway disease (upper airway stenosis, bronchitis, occasionally associated with bronchiectasis, and chronic bronchiolitis), interstitial lung disease, necrotic parenchymal nodules and serositis [2]. CAmus et al. [2] published the largest series with data in 33 cases, followed by Higenbottam et al. [4], Butland et al. [6] and Kraft et al. [8] with 10, 7 and 6 cases, respectively. More than $80 \%$ of all reported cases had ulcerative colitis, whilst the remainder suffered from Crohn's disease [2]. Respiratory involvement may be different in patients with ulcerative colitis and Crohn's disease [2]. Granulomatous involvement and oedema of the larynx, trachea and bronchi have been reported only in Crohn's disease. Conversely, chronic bronchiolitis and necrobiotic nodules have, so far, been reported only in ulcerative colitis [2]. Abnormal lung function was found in $38 \%$ of patients with ulcerative colitis and in 54\% with Crohn's disease despite normal chest X-rays and lack of pulmonary symptoms $[10,11]$. The pattern of ventilatory impairment was predominantly obstructive in ulcerative colitis and restrictive in Crohn's disease [10-12].

Severe upper airway inflammation has previously been mentioned in six cases, the subglottic area being mainly involved $[2,5,13,14]$. In contrast, we found the most important site of involvement at the vocal cord level, with decreasing pseudotumoral narrowing in the lower trachea and mainstem bronchi.

In the cases so far published, including the case reported here, cough and hoarseness appeared early and were often misinterpreted. In contrast to chronic bronchial suppuration or bronchiectasis, which usually developed in patients with quiescent IBD, the majority of patients with upper airway obstruction had active IBD [2, 13, 14].

No other cause was found for the laryngotracheobronchitis in our patient. Differential diagnosis included infectious and noninfectious inflammatory processes, neoplasia and exogenous factors. Viral serology was negative, and repeated sputum tests and blood cultures revealed no evidence of bacterial infection. Various antibiotics had no effect on clinical or laboratory parameters of inflammation. The temporal association with the switch from sulphasalazine to mesalazine raised the possibility of an adverse drug effect. Acute alveolitis has recently been described in patients taking mesalazine [15], but there have been no reports of large airway involvement. Moreover, the obstruction resolved despite continued treatment with mesalazine. Isolated subglottic stenosis has been associated with several other disorders, including prior endotracheal intubation, sarcoidosis, amyloidosis, Wegener's granulomatosis, tuberculosis, midline granuloma, cutaneous pemphigus, relapsing polychondritis, lupus erythematosus, and tracheobronchopathia osteoplastica [16]. A series of six patients with subglottic stenosis has recently been reported in systemic, ANCA positive vasculitis [16]. ANCA was measured in 12 cases of IBD with respiratory involvement and was found to be positive in four [2]. There was no correlation between ANCA and the pattern of respiratory involvement.

Histological examination of the tracheal mucosa showed chronic inflammation. The findings at concurrently performed colonic mucosal biopsy were consistent with moderately active ulcerative colitis. The similar pattern of inflammation suggests that the alterations of the upper airways and the colon might have been triggered by the same disease process. As HigenbotTAm et al. [4] suggested, the common embryological roots could explain the involvement of the respiratory system in some patients with IBD.

Our patient showed a good immediate and mediumterm response to corticosteroids, with rapid clinical improvement and resolution of serological parameters of inflammation. The obstructive ventilatory impairment proved fully reversible. The response to corticosteroids has been mentioned by several authors [1-7, 17], with a dramatic effect following methylprednisolone in some cases. Laser beam ablation has been proposed for patients with life-threatening airway obstruction, and those with disease refractory to corticosteroids [2].

In our case, the medium-term outcome was good, the patient remaining in remission 8 months after diagnosis, including 1 month without oral corticosteroids. In four of the six previously reported cases of subglottic stenosis, the outcome was also favourable, the patients reporting few or no symptoms $[2,15]$. One patient died after an attempt at tracheal dilatation [5], whilst another died of endotoxin shock related to colitis [16].

Our report supports the contention that severe inflammatory upper airway stenosis is part of the spectrum of IBD-related respiratory manifestations.

\footnotetext{
Acknowledgements: The authors wish to thank R. Birrer for preparing the manuscript, C. Kreeger for translating the text and P. Boyle for editorial assistance. The case was presented at the annual meeting of the Swiss Society of Pneumology, October 9, 1993 in Lugano, and published in abstract form (Schweiz Med Wschr 1993; 123 (Suppl. 53): 27).
}

\section{References}

1. Greenstein AJ, Janowitz HD, Sachar DB The extraintestinal complications of Crohn's disease and ulcerative colitis: a study of 700 patients. Medicine 1976; 55: 401-412.

2. Camus P, Piard F, Ashcroft T, Gal AA, Colby TV. The lung in inflammatory bowel disease. Medicine 1993; 72: 151-183.

3. Germann PP, Schölmerich J, Costabel U, Guzman J, Pausch J, Gerok W. Koinzidenz von Colitis ulcerosa und Lungenfibrose - eine seltene extraintestinale Manifestation chronisch entzündlicher Darmerkrankungen? Med Klin 1988; 83: 461-463.

4. Higenbottam T, Cochrane GM, Clark T, Turner D, Millis $\mathrm{R}$, Seymour W. Bronchial disease in ulcerative colitis. Thorax 1980; 35: 581-585.

5. Wilcox P, Miller R, Miller G, et al. Airway involvement in ulcerative colitis. Chest 1987: 92: 18-22. 
6. Butland RJA, Cole P, Citron KM, Turner-Warwick M. Chronic bronchial suppuration and inflammatory bowel disease. Q J Med 1981; 197: 63-75.

7. Hold G, Bolognini G, Russi E. Pulmonale Veränderungen bei Colitis ulcerosa. Schweiz Med Wschr 1992; 122: 1363-1368.

8. Kraft SC, Earle RH, Roesler M, Esterly JR. Unexplained bronchopulmonary disease with inflammatory bowel disease. Arch Intern Med 1976; 136: 454-459.

9. Sargent D, Sessions JT, Fairman RP. Pulmonary vasculitis complicating ulcerative colitis. South Med J 1985; 78: 624-625.

10. Heatley RV, Thomas P, Prokipchuk EJ, Gauldie J, Sjenjewicz DJ, Bienenstock J. Pulmonary function abnormalities in patients with inflammatory bowel disease. $Q J$ Med 1982; 203: 241-250.

11. Sommer H, Schmidt M, Gruber KD. Lungenfunktionsstörungen bei Colitis ulcerosa und Morbus Crohn Dtsch Med Wschr 1986; 111: 812-815.

12. Neilly JB, Main ANH, McSharry C, Murray J, Russell
RI, Moran F. Pulmonary abnormalities in Crohn's disease. Respir Med 1989; 83: 487-490.

13. Collins JR. Adverse reactions to salicylazosulfapyridine (Azulfidine) in the treatment of ulcerative colitis. South Med $J$ 1968; 61: 354-358.

14. Karasalihoglu A, Kutlu K, Yilmaz T. Obstruction laryngotracheale en cas de colite ulcereuse. Rev Laryngol 1988; 109: 469-471.

15. Lagler U, Schulthess HK, Kuhn M. Akute Alveolitis unter Mesalazin. Schweiz Med Wschr 1992; 122: 13321334.

16. Vries N de, Gans ROB, Donker AJM, Goldschmeding R, Hoomtje SJ, Snow GB. Autoantibodies against constituents of neutrophils in the diagnosis and treatment of (isolated) subglottic stenosis. Arch Otolaryngol Head Neck Surg 1992; 118: 1120-1123.

17. McCulloch AJ, McEvoy A, Jackson JD, Jarvis EH. Severe steroid responsive pneumonitis associated with pyoderma gangrenosum and ulcerative colitis. Thorax 1985; 40: 314-315. 